\title{
FORMULASI DAN UJI STABILITAS FISIK SEDIAAN KRIM EKSTRAK ETANOL DAUN SESEWANUA (Clerodendron squamatum Vahl.)
}

\author{
Meyla C.M. Pratasik ${ }^{1)}$, Paulina V.Y. Yamlean ${ }^{1)}$, Weny I. Wiyono ${ }^{1)}$ \\ ${ }^{1)}$ Program Studi Farmasi FMIPA UNSRAT Manado, 95115
}

\begin{abstract}
Sesewanua Leaves (Clerodendron squamatum Vahl.) have the potential to be made as skin care cosmetic preparations but must be in the right formulation to achieve the desired effect. The aim of this study was to determine the physical stability of a cream from Sesewanua leaf extract. This study used a experimental method by making ethanol extract of Sesewanua leaves with a concentration of $0.5 \%$ and physical stability test. Physical evaluation was carried out before and after cycling test through organoleptic observation, homogenety test, $\mathrm{pH}$ test, dispersion test, adhesion test, viscosity test, centrifugation test and cream type determination. The results of the physical evaluation showed that F1 without Sesewanua leaf extract and F2 with Sesewanua leaf extract creams met the requirements of physical stability, so can be concluded that Sesewanua leaf extract can be formulated into cream preparations with concentration of $0.5 \%$ which is physically stable before and after cycling test.
\end{abstract}

Keywords: Sesewanua Leaves, Cream, Physical Stability

\begin{abstract}
ABSTRAK
Daun Sesewanua (Clerodendron squamatum Vahl.) berpotensi untuk dibuat sebagai sediaan kosmetik perawatan kulit namun harus dengan formulasi yang tepat agar mencapai efek yang diinginkan. Penelitian ini bertujuan untuk mengetahui stabilitas fisik sediaan krim ekstrak daun sesewanua. Penelitian ini menggunakan metode eksperimental dengan membuat krim ekstrak etanol daun Sesewanua dengan konsentrasi 0,5\% dan uji stabilitas fisik. Evaluasi fisik dilakukan sebelum dan sesudah cycling test melalui pengamatan organoleptis, uji homogenitas, uji $\mathrm{pH}$, uji daya sebar, uji daya lekat, uji viskositas, uji sentrifugasi dan penentuan tipe krim. Hasil evaluasi fisik menunjukkan krim F1 tanpa ekstrak daun Sesewanua dan F2 dengan ekstrak daun Sesewanua memenuhi persyaratan stabilitas fisik. Berdasarkan hasil penelitian dapat disimpulkan ekstrak daun sesewanua dapat diformulasi menjadi sediaan krim dengan konsentrasi $0,5 \%$ yang stabil secara fisik sebelum dan sesudah cycling test.
\end{abstract}

Kata Kunci : Daun Sesewanua, Krim, Stabilitas Fisik 


\section{PENDAHULUAN}

Kemajuan ilmu pengetahuan modern yang semakin pesat dan canggih saat ini, tidak dapat dapat mengesampingkan obat alami. Selain itu, masih banyak kurangnya pengetahuan dan informasi mengenai berbagai jenis tumbuhan yang dipakai sebagai obat alami untuk pengobatan tertentu yang dapat dikembangkan menjadi suatu formulasi (Dewi et al., 2014).

Sesewanua (Clerodendron squamatum Vahl.) secara empiris telah digunakan oleh masyarakat dibeberapa daerah di Sulawesi Utara untuk mengobati berbagai macam penyakit seperti demam, patah tulang, dan penurun bengkak. Daun Sesewanua ini berpotensi untuk dibuat sebagai sediaan kosmetik perawatan kulit namun harus dengan formulasi yang tepat agar mencapai efek yang diinginkan (Draelos dan Thaman,2006).

Kestabilan suatu zat merupakan suatu yang harus diperhatikan dalam membuat suatu formulasi atau sediaan farmasi. Adanya zat aktif diperkirakan mempengaruhi kestabilan fisik dari setiap formulasi krim yang dibuat (Dewi et al., 2014). Berdasarkan hal tersebut maka dilakukan penelitian tentang formulasi dan uji stabilitas fisik sediaan krim ekstrak etanol daun Sesewanua (Clerodendron squamatum Vahl.).

\section{METODE PENELITIAN}

\section{Alat}

Alat-alat gelas (Iwaki Pyrex), blender, batang pengaduk, kertas saring, pot krim, corong,timbangan analitik ( $88 A D A M), \mathrm{pH}$ meter (CP-505), thermometer, gelas objek, cawan petri, lumpang, stopwatch, pemberat, alat uji daya lekat,hotplatestirrer, viskometer Brookfield model DV-E seri LV, sentrifugasi (CLEMENTS GS 150), oven (ECOCELL), lemari es (SAMSUNG).

\section{Bahan}

Ekstrak daun Sesewanua, setil alkohol, asam stearat, trietanolamin, paraffin cair, propilen glikol, metil paraben (nipagin), propil paraben (nipasol), aquadest, etanol 96\%, metilen biru.

\section{Pengambilan Sampel}

Sampel daun Sesewanua diambil di kecamatan Mapanget kota Manado, selanjutnya disortasi basah lalu dikeringanginkan. Daun yang kering dihaluskan dengan cara diblender dan diayak sehingga diperoleh simplisia daun Sesewanua.

\section{Ekstrasi}

Sebanyak 500 g simplisia kering dimaserasi menggunakan pelarut etanol $96 \%$ sebanyak $1500 \mathrm{~mL}$ sampai semua sampel terendam oleh pelarut. Ekstraksi dilakukan dengan cara maserasi selama 3x24 jam dengan beberapa kali pengadukan. Ekstrak hasil maserasi kemudian disaring sehingga diperoleh filtrat dan residu. Selanjutnya dilakukan remaserasi selama $2 \times 24$ jam. Filtrat yang diperoleh kemudian dievaporasi pada suhu $40^{\circ} \mathrm{C}$ sampai diperoleh ekstrak kental.

\section{Formulasi Sediaan Krim}

\section{Tabel 1. Formula Krim Ekstrak Etanol} Daun Sesewanua

\begin{tabular}{lcc}
\hline \multirow{2}{*}{\multicolumn{1}{c}{ Bahan }} & \multicolumn{2}{c}{ Formula } \\
\cline { 2 - 3 } & I & II \\
\hline Ekstrak daun Sesewanua & - & $0,5 \%$ \\
Setil alkohol & $2 \%$ & $2 \%$ \\
Trietanolamin & $2 \%$ & $2 \%$ \\
Asam stearat & $12 \%$ & $12 \%$ \\
Propilen glikol & $10 \%$ & $10 \%$ \\
Paraffin cair & $5 \%$ & $5 \%$ \\
Metil paraben & $0,1 \%$ & $0,1 \%$ \\
Propil paraben & $0,08 \%$ & $0,08 \%$ \\
Aquadest & Ad $100 \%$ & Ad $100 \%$ \\
\hline
\end{tabular}

\section{Pembuatan Krim}


Alat dan bahan disiapkan. Fase minyak dibuat dengan melebur setil alkohol, paraffin cair, asam stearat dan propil paraben pada suhu $70^{\circ} \mathrm{C}$. Fase air dibuat dengan melarutkan metil paraben dalam propilen glikol dan ditambahkan trietanolamin pada suhu $70{ }^{\circ} \mathrm{C}$. Krim dibuat dengan mencampurkan fase minyak ke dalam fase air sambil diaduk sampai terbentuk krim yang homogen. Selanjutnya untuk pembuatan krim F2 dibuat dengan mencampurkan ekstrak etanol daun Sesewanua $0,5 \%$ ke dalam basis.

\section{Uji Stabilitas Fisik}

1. Pengamatan Organoleptis Krim

Uji organoleptik dilakukan dengan melihat perubahan warna, bau tengik, dan adanya pemisahan fase (Elya et.al.,2013).

2. Pengujian Homogenitas Krim

Tes homogenitas dilakukan dengan cara krim ditimbang $1 \mathrm{~g}$ dioleskan pada plat kaca. Sediaan krim dikatakan homogen bilamana tidak menunjukkan adanya partikel-partikel yang menggumpal atau tidak bercampur (Depkes,1979).

3. Pengukuran $\mathrm{pH}$

Tes $\mathrm{pH}$ dilakukan dengan menggunakan $\mathrm{pH}$ meter. Elektroda pengukur dicelupkan sehingga ujung elektroda tercelup semua, $\mathrm{pH}$ yang diperoleh dicatat. $\mathrm{pH}$ krim harus sesuai dengan $\mathrm{pH}$ kulit yaitu 4,2-6,5 (Wasitaatmadja,1997).

4. Daya Sebar

Krim ditimbang $1 \mathrm{~g}$, lalu diletakan di atas plat kaca, biarkan 1 menit, ukur diameter sebar krim, kemudian ditambah dengan beban $50 \mathrm{~g}$, beban didiamkan selama 1 menit,lalu diukur diameter sebarnya. (Rahmawati, et al.,2010)

5. Uji Viskositas
Viskositas krim diukur dengan menggunakan $L V$ viscometer BrookField dan masing-masing formula direplikasi tiga kali. Sediaan sebanyak 30 gram dimasukkan ke dalam pot salep, kemudian dipasang spindle dan rotor dijalankan. Hasil viskositas dicatat (Rahmawati et al., 2010).

6. Daya Lekat

Sebanyak 0,25 gram krim dioleskan pada plat kaca, kedua plat ditempelkan sampai plat menyatu. Krim diantara plat kaca ditekan dengan beban 50 g selama 5 menit. Plat kaca yang saling menempel dipasang pada alat uji daya lekat dan dilepas dengan beban $80 \mathrm{~g}$, kemudian dicatat waktu saat kedua plat tersebut lepas. Replikasi dilakukan sebanyak tiga kali (Rahmawati et al., 2010).

7. Pengujian Stabilitas Krim dengan Sentrifugasi

5 g sampel krim ditempatkan dalam tabung sentrifugasi dan disentrifugasi $3750 \mathrm{rpm}$ selam 5 jam atau 5000-10000 rpm selama 30 menit.Pengujian ini dilakukan untuk mengetahui adanya pemisahan fase pada sediaan krim (Handali, et al., 2011).

8. Metode Cycling Test

Salah satu cara mempercepat evaluasi kestabilan adalah dengan cycling test. Uji cycling test ini dilakukan sebanyak 6 siklus. Sediaan krim disimpan pada suhu dingin $\pm 4^{\circ} \mathrm{C}$ selama 12 jam lalu dikeluarkan dan ditempatkan pada suhu $\pm 40^{\circ} \mathrm{C}$, proses ini dihitung 1 siklus.Kondisi fisik krim dibandingkan selama percobaan dengan sediaan sebelumnya (Rieger, 2000)

9. Penentuan Tipe Emulsi

a. Metode Pengenceran

Krim yang telah dibuat dimasukkan ke dalam gelas piala kemudian diencerkan dengan air. Jika krim dapat diencerkan 
maka tipe emulsinya adalah tipe M/A sebaliknya jika tidak dapat diencerkan maka tipe emulsinya A/M (Sanjay,2003).

b. Metode Dispersi Larutan Zat Warna Krim yang telah dibuat dimasukkan kedalam gelas piala kemudian ditetesi beberapa tetes larutan metilen biru. Jika warna biru segera terdispersi keseluruh emulsi maka tipe emulsinya M/A sebaliknya jika warna biru tidak terdispersi seluruhnya maka tipe emulsinya A/M (Sanjay, 2003).

\section{HASIL DAN PEMBAHASAN}

Hasil ekstraksi daun Sesewanua dengan menggunakan pelarut etanol $96 \%$ erupa ekstrak kental berwarna hijau muda dan berbau khas. Dari 500 gram serbuk simplisia daun Sesewanua diperoleh sebanyak 29,2 gram ekstrak kental sehingga diperoleh rendemen sebesar 5,84\%.

\section{Pengamatan Organoleptis}

Tabel 2. Hasil Pengamatan Organoleptis

\begin{tabular}{lcccc}
\hline \multirow{2}{*}{ Pengamatan } & \multicolumn{2}{c}{ Sebelum cycling test } & \multicolumn{2}{c}{ Sesudah cycling test } \\
\cline { 2 - 5 } & F1 & F2 & F1 & F2 \\
\hline Warna & Putih & Hijau Muda & Putih & Hijau Muda \\
Bau & Khas Basis & Khas & Khas Basis & Khas Sesewanua \\
& Krim & Sesewanua & Krim & \\
Bentuk & Setengah & Setengah & Setengah & Setengah Padat \\
& Padat & Padat & Padat & \\
\hline
\end{tabular}

Hasil pengamatan organoleptis krim F1 memiliki bentuk semi padat dan lembut layaknya krim, memiliki bau khas basis dan warna putih. Pada sediaan krim F2 memiliki bentuk semi padat dan lembut, memiliki bau khas Sesewanua dan berwarna hijau muda.
Setelah dilakukan cycling test selama 6 siklus, sediaan krim F1 dan F2 tidak menimbulkan perubahan warna, bau dan bentuk sehingga dapat disimpulkan krim F1 dan F2 memenuhi persyaratan stabilitas fisik.

\section{Uji Homogenitas}

Tabel 3. Hasil Uji Homogenitas

\begin{tabular}{ccc}
\hline Sediaan & $\begin{array}{c}\text { Homogenitas } \\
\text { (sebelum cycling test) }\end{array}$ & $\begin{array}{c}\text { Homogenitas } \\
\text { (sesudah cycling test) }\end{array}$ \\
\hline F1 & $(+)$ & $(+)$ \\
F2 & $(+)$ & $(+)$ \\
\hline
\end{tabular}

Sediaan krim yang baik harus homogen dan bebas dari partikel-partikel yang masih menggumpal. Hasil homogenitas sebelum dan sesudah cycling test menunjukkan bahwa sediaan krim ekstrak etanol daun sesewanua $0,5 \%$ homogen karena tidak terdapat butiranbutiran saat digosokkan pada tangan.

\section{Uji pH}


PHARMACON- PROGRAM STUDI FARMASI, FMIPA, UNIVERSITAS SAM RATULANGI,

Volume 8 Nomor 2 Mei 2019

Tabel 4. Hasil Uji pH

\begin{tabular}{ccccc}
\hline \multirow{2}{*}{ Replikasi } & \multicolumn{2}{c}{ Sebelum cycling test } & \multicolumn{2}{c}{ Sesudah cycling test } \\
\cline { 2 - 5 } & F1 & F2 & F1 & F2 \\
\hline 1 & 6,47 & 5,34 & 5,66 & 4,89 \\
2 & 6,50 & 5,57 & 5,62 & 4,84 \\
3 & 6,49 & 5,58 & 5,53 & 4,90 \\
Rata-rata & 6,48 & 5,49 & 5,60 & 4,87 \\
\hline
\end{tabular}

Pengukuran $\mathrm{pH}$ ini bertujuan untuk mengetahui apakah krim yang dibuat telah aman dan tidak mengiritasi kulit saat digunakan. Menurut Tranggono (2007), syarat $\mathrm{pH}$ sediaan topikal yang baik adalah sesuai dengan $\mathrm{pH}$ alami kulit yaitu 4,5-6,5.Hasil pengujian $\mathrm{pH}$ menunjukkan krim $\mathrm{F} 1$ dan F2 $\mathrm{pH}$ nya berada diantara rentang $\mathrm{pH}$ sediaan topikal yang baik.

\section{Pengujian Daya Sebar}

Tabel 5. Hasil Pengujian Daya Sebar

\begin{tabular}{ccccc}
\hline \multirow{2}{*}{ Replikasi } & \multicolumn{2}{c}{ Sebelum cycling test } & \multicolumn{2}{c}{ Sesudah } \\
& $\mathrm{F} 1$ & $\mathrm{~F} 2$ & $\mathrm{~F} 1$ & $\mathrm{~F} 2$ \\
\cline { 2 - 5 } & $5 \mathrm{~cm}$ & $5,8 \mathrm{~cm}$ & $5,5 \mathrm{~cm}$ & $5,3 \mathrm{~cm}$ \\
2 & $5,8 \mathrm{~cm}$ & $5,4 \mathrm{~cm}$ & $5,7 \mathrm{~cm}$ & $5 \mathrm{~cm}$ \\
3 & $5,4 \mathrm{~cm}$ & $6 \mathrm{~cm}$ & $5 \mathrm{~cm}$ & $5,5 \mathrm{~cm}$ \\
Rata-rata & $5,4 \mathrm{~cm}$ & $5,7 \mathrm{~cm}$ & $5,4 \mathrm{~cm}$ & $5,2 \mathrm{~cm}$ \\
\hline
\end{tabular}

Pengujian daya sebar bertujuan untuk mengetahui kemampuan basis krim menyebar sehingga dapat dilihat kemudahan pengolesan sediaan ke kulit. Daya sebar yang baik menyebabkan kontak antara obat dengan kulit menjadi luas, sehingga absorpsi ke kulit berlangsung cepat. Menurut Garg (2002), diameter daya sebar yang nyaman dalam penggunaanya untuk sediaan semisolid yaitu 5-7 cm. Hasil uji daya sebar menunjukkan F1 dan F2 memenuhi standar daya sear sediaan yang baik.

\section{Pengujian Daya Lekat}

Tabel 6. Hasil Pengujian Daya Lekat

\begin{tabular}{|c|c|c|c|c|}
\hline \multirow[t]{2}{*}{ Replikasi } & \multicolumn{2}{|c|}{ Sebelum cycling test } & \multicolumn{2}{|c|}{ Sesudah cycling test } \\
\hline & $\begin{array}{c}\mathrm{F} 1 \\
\text { (Detik) }\end{array}$ & $\begin{array}{c}\mathrm{F} 2 \\
\text { (Detik) }\end{array}$ & $\begin{array}{c}\mathrm{F} 1 \\
\text { (Detik) }\end{array}$ & $\begin{array}{c}\mathrm{F} 2 \\
\text { (Detik) }\end{array}$ \\
\hline 1 & 17,38 & 8,62 & 16,68 & 12,45 \\
\hline 2 & 13,19 & 9,68 & 11,02 & 10,58 \\
\hline 3 & 11,44 & 8,12 & 12,26 & 9,13 \\
\hline Rata-rata & 14 & 8,80 & 13,32 & 10,72 \\
\hline
\end{tabular}

Pengujian daya lekat bertujuan untuk mengetahui waktu yang dibutuhkan krim untuk melekat pada kulit. Daya lekat yang baik memungkinkan krim tidak mudah lepas dan semakin lama melekat pada kulit, sehingga dapat menghasilkan efek yang diinginkan. Menurut Rachmalia et al., (2016), persyaratan daya lekat yang baik untuk sediaan topikal adalah lebih dari 4 detik. Hasil uji daya lekat menunjukkan F1 dan F2 memenuhi syarat sediaan topikal yang baik. 


\section{Pengujian Viskositas}

Tabel 7. Hasil Pengujian Viskositas

\begin{tabular}{ccccc}
\hline Replikasi & \multicolumn{2}{c}{ Sebelum cycling test } & \multicolumn{2}{c}{ Sesudah cycling test } \\
\cline { 2 - 5 } & $\begin{array}{c}\text { F1 } \\
(\mathrm{mPa} . \mathrm{s})\end{array}$ & $\begin{array}{c}\mathrm{F} 2 \\
(\mathrm{mPa} . \mathrm{s})\end{array}$ & $\begin{array}{c}\text { F1 } \\
(\mathrm{mPa} . \mathrm{s})\end{array}$ & $\begin{array}{c}\mathrm{F} 2 \\
(\mathrm{mPa} . \mathrm{s})\end{array}$ \\
\hline 1 & 18,200 & 10,200 & 23,900 & 12,800 \\
2 & 17,500 & 9000 & 23,600 & 12,600 \\
3 & 18,400 & 11,100 & 25,500 & 15,900 \\
Rata-rata & 18,033 & 10,100 & 24,333 & 13,766 \\
\hline
\end{tabular}

Pengujian viskositas krim ekstrak daun Sesewanua bertujuan untuk mengetahui besar tahanan yang dihasilkan krim. Menurut Wasitaatmadja (1997), persyaratan viskositas yang baik pada sediaan semi solid adalah sebesar 4000-40.000 cPs. Berdasarkan hasil pengujian menunjukkan krim F1 dan F2 mengalami perubahan tapi masih memenuhi persyaratan stabilitas fisik. Perubahan viskositas dapat dipengaruhi beberapa hal seperti pencampuran, pengadukan, pemilihan emulgator dan proporsi fase terdispersi (Alfred et al., 1993).

\section{Pengujian Sentrifugasi}

Tabel 8. Hasil Pengujian Sentrifugasi

\begin{tabular}{ccc}
\hline Sediaan & Sebelum cycling test & Sesudah cycling test \\
\hline F1 & Tidak terjadi pemisahan fase & Tidak terjadi pemisahan fase \\
F2 & Tidak terjadi pemisahan fase & Tidak terjadi pemisahan fase \\
\hline
\end{tabular}

Pengujian ini dilakukan untuk mengetahui kestabilan krim setelah pengocokan dengan kecepatan tinggi menggunakan alat sentrifugasi. Krim dimasukkan ke tabung eppendorf dengan kecepatan $3750 \mathrm{rpm}$ selama
5 jam yang ekivalen dengan efek gravitasi selama 1 tahun.Hasil pengujian sentrifugasi menunjukan bahwa krim F1 dan F2 tidak terjadi pemisahan fase dan stabil secara fisik.

\section{Pengujian Tipe Emulsi}

Tabel 9. Hasil Pengujian Tipe Emulsi

\begin{tabular}{lcccc}
\hline \multirow{2}{*}{ Uji } & \multicolumn{2}{c}{ Sebelum cycling test } & \multicolumn{2}{c}{ Sesudah cycling test } \\
\cline { 2 - 5 } & F1 & F2 & F1 & F2 \\
\hline Pengenceran & M/A & M/A & M/A & M/A \\
Dispersi zat Warna & M/A & M/A & M/A & M/A \\
\hline
\end{tabular}


Penentuan tipe emulsi dilakukan untuk mengetahui tipe $\mathrm{A} / \mathrm{M}$ atau $\mathrm{M} / \mathrm{A}$ pada suatu sediaan krim. Hasil pengujian tipe emulsi krim menunjukkan F1 dan F2 mempunyai tipe emulsi M/A, baik dengan uji pengenceran maupun uji disperse zat warna larutan metilen biru. Hal ini disebabkan karena volume fase terdispersi (fase minyak) yang digunakan dalam krim lebih kecil dari fase pendispersi (fase air), sehingga globul-globul minyak akan terdispersi ke dalam fase air dan membentuk emulsi tipe M/A.

\section{KESIMPULAN}

Formulasi krim F1 tanpa ekstrak etanol daun Sesewanua dan F2 dengan ekstrak etanol daun Sesewanua konsentrasi $0,5 \%$ menghasilkan krim yang yang stabil secara fisik dan memenuhi syarat sediaan topikal yang baik sebelum maupun sesudah cycling test.

\section{DAFTAR PUSTAKA}

Alfred, M., James, S., Arthur,C. 1993. Farmasi Fisik, Dasar-dasar Kimia Fisik dalam Ilmu Farmasetik Jilid III. UI Press, Jakarta.

Depkes RI. 1979. Farmakope Indonesia, Edisi III. Departemen Kesehatan RI, Jakarta.

Dewi, R., Anwar, E., Yunita, K.S. 2014. Uji Stabilitas Fisik Formula Krim yang Mengandung Ekstrak Kacang Kedelai (Glycine max). Universitas Indonesia, Depok.

Draelos, Z. D., dan Thaman, L. A. 2006. Cosmetic Formulation of Skin Care Product. Taylor and Francis Group, New York. 377.

Elya, Berna., Dewi, R., Haqqi, M Budiman. 2013. Antioxidant Cream of Solanum lycopersicum L. International Journal of PharmTech Research. West Java University of Indonesia.

Garg, A., Aggarwal, D., Garg, S., \& Singla, A.K. 2002. Spreading of Semisolid Formulations An Update (http://www.pharmtech.com) [diakses pada 29 Maret 2019].
Handali,S., Hosseini, H., Ameri, A., Moghimipour, E. 2011. Formulation and evaluation of an antibacterial cream from Oxalis corniculata aqueous extract. Medicinal Plant Research Center, Ahvaz Jundishapur University of Medical Sciences, Ahvaz, Iran.

Rachmalia N., Mukhlishah I., Sugihartini N., Yuwono T. 2016. Daya Iritasi dan Sifat Fisik Sediaan Salep Minyak Atsiri Bunga Cengkih (Syzigium aromaticum) pada Basis Hidrokarbon. Maj. Farmaseutik. 12:372-376.

Rahmawatti, D., Sukmawati, A., Indrayudha P. 2010. Formulasi Krim Minyak Atsiri Rimpang Temu Giring (Curcuma heyneana Val \& Zijp), Uji Sifat Fisik dan Daya Antijamur terhadap Candida albicans secara invitro. Maj.Obat Tradisional. 15: 56-63.

Rieger, M,. 2000. Harry's Cosmeticology $8^{\text {th }}$ Edition. Chemical Publishing Co Inc, New York.

Sanjay, B., Singla, D., and Sakhuja N,. 2003. Stability Testing Guidelines : Stability Testing Of New Drug Substances And Products, ICH Steering Committee. Journal of Applied Pharmaceutical Science. 68(225): 129-138.

Tranggono \& Latifah, F. 2007. Buku Pegangan Ilmu Pengetahuan Kosmetik. Penerbit PT Gramedia Pustaka Utama, Jakarta

Wasitaatmadja, M.S,. 1997. Penuntun Ilmu Kosmetik Medik. Universitas Indonesia Press, Jakarta. 